\title{
Proceeding
}

Supplementary Issue: Autumn Conferences of Sports Science. Costa Blanca Sports Science Events, 2-3 November 2018.

Alicante, Spain

\section{Characteristics of strength in subjects with cardiovascular disease}

\author{
STEFANO SCARPA ${ }^{1}$, ALESSANDRA NART ${ }^{2}$ \\ 1 University "Giustino Fortunato" of Benevento, Italy \\ 2University of Padua, Italy
}

\begin{abstract}
The aim of our work was to estimate the maximum strength of the upper and lower limbs (quadriceps, gastrocnemius, biceps, triceps, deltoid) in a group of patients affected by various cardiovascular diseases and compare it with that of a group of healthy and sedentary subjects $(n=20)$. We also wanted to assess whether there were differences in the maximum strength between different groups of cardiovascular diseases. This study presents many innovative elements, primarily two ones: (a) to recognize the importance of muscle strength as a health component in heart patients; (b) to establish a method for the assessment of strength based on estimation of $1 \mathrm{RM}$. Here are presented the patients recruited on the basis of the basic pathology: 45 patients had chronic heart failure (CHF) in clinical stability for at least 3 months, class NYHA II-III; 21 patients had peripheral obliterative arteriopathy with claudication (POAC, stage lla of Fontaine); 22 patients had undergone coronary angioplasty (coronary artery disease - CAD); 6 patients had undergone orthotopic cardiac transplant (HT) for at least 6 months. Chronic cardiovascular patients are characterized by a muscular impairment that parallels the history of the disease. Key words: Cardiovascular disease; Strength; Upper limb; Lower limb.
\end{abstract}

\section{Cite this article as:}

Scarpa, S., \& Nart, A. (2019). Characteristics of strength in subjects with cardiovascular disease. Journal of Human Sport and Exercise, 14(1proc), S92-S99.

doi:https://doi.org/10.14198/jhse.2019.14.Proc1.11

Corresponding author. University of Padua, Italy.

E-mail: alessandra.nart@unipd.it

Supplementary Issue: Autumn Conferences of Sports Science. Costa Blanca Sports Science Events, 2-3 November 2018. Alicante, Spain.

JOURNAL OF HUMAN SPORT \& EXERCISE ISSN 1988-5202

(C) Faculty of Education. University of Alicante.

doi:10.14198/jhse.2019.14.Proc1.11 


\section{INTRODUCTION}

Muscular strength is a fundamental component of exercise and functional capacity, particularly in patients with chronic disease. Muscular strength is positively related to independence, quality of life and ability to perform activities of daily living; and it play also a crucial role in reducing disability and in the prevention of chronic disease ${ }^{1,2}$.

Patients diagnosed with chronic heart disease display diminished exercise tolerance. This can be attributed not only to a reduction in aerobic capacity, as has been amply demonstrated in the literature ${ }^{3}$, but probably also to a strength deficit such as muscle structure alterations, including muscle weakness and volume reduction, and other pathophysiological mechanisms that underlie both aerobic and strength. The result is that exercise intolerance is a common clinical manifestation in cardiovascular patients ${ }^{4}$.

Indeed, back in the early 1990s, Drexler demonstrated that patients diagnosed with chronic heart failure (CHF) exhibit a particular pattern of myopathy characterized by muscular atrophy and a shift in the distribution of fiber type with a reduced oxidative capacity ${ }^{5}$. The initial loss of type I fibers, which is responsible for endurance, is followed by a consecutive increase in type II fibers. While until not long ago three types of muscle fibers were identified (I; lla; llb), currently fibers of the skeletal muscle are classified into four types according to their biochemical characters: (a) slow-twitch type I fatigue-resistant fibers; (b) fast-twitch type Ila fatigue-resistant fibers; (c) fast-twitch type IIx fibers with intermediate fatigue-resistance; (d) and fasttwitch type llb fatigable fibers 6 .

Recently, Katsuki et al. (2015) demonstrated the activation of Wnt signalling inducted by C1q that seems contributes to fiber type shift toward fatigable fiber. So fiber type shift toward more fatigable type llb fiber is one of the characteristics observed during the development of skeletal myopathy in cardiovascular patients ${ }^{7}$.

Besides all this, the story of illness leads the patient to a sedentary lifestyle then to atrophy and muscle weakness, and consequently to a "cascade" of events responsible for the diminished exercise tolerance and strength deficit. Strength decreases with the severity of disease for reasons that are in part explained (see above) and in part still unknown.

Poor muscle strength is associated with mortality: persons with poorer baseline strength are more likely to die over a follow-up period of 30 years. Although the mechanism explaining the association between muscle strength and mortality risk remains to be explored, probably the risk of mortality is due to low levels of muscle mass $^{8}$.

Maximum strength of the quadriceps muscle in patients with $\mathrm{CHF}$ is an important prognostic index; indeed, in the opinion of some, it is superior to the $\mathrm{VO}_{2} \mathrm{max}^{9}$. Handgrip strength can predict long term mortality in patients with $\mathrm{CHF}^{10}$ and 6 -month mortality in population with coronary artery disease $(\mathrm{CAD})^{11}$. Other studies found that muscle strength in men without heart disease was inversely and independently associated with all-cause mortality ${ }^{12,13}$.

While muscular impairment in CHF patients has been amply studied, there are limited case-reports on the strength characteristics of patients affected by other cardiovascular pathologies, such as CAD without ventricular dysfunction. Less attention has been directed also to the issue of post heart transplant (HT) functional capacity ${ }^{14}$. 
This study presents many novelty and innovative elements: (a) to recognize the importance of muscle strength as a health component in heart patients (not only the aerobic component as in the past); (b) to establish a method for the assessment of strength based on estimation of 1RM: (b 1 ) allowing partial information on the severity and history of the disease, $\left(b_{2}\right)$ establishing a targeted rehabilitation program (based on \% of $1 \mathrm{RM}),\left(\mathrm{b}_{3}\right)$ presenting a protocol that is replicable at any medical sports centre or gymnasium (with simple tools) not just for doing research but also for those who deal with clinical activity and physical training (being able to establish the baseline and to compare the various diseases on a cross sectional design as well as improvements of each patient in a longitudinal direction (other studies have not found who set out with the same goal as will be explained in the discussion stage $)^{15,16}$.

Taking into account all these premises, the aim of this study was therefore to estimate maximum dynamic strength of the upper and lower limbs (quadriceps, gastrocnemius, biceps, triceps, deltoid) in a group of patients affected by various cardiovascular diseases and compare it with that of a group of healthy and sedentary subjects $(n=20)$. We also wanted to assess whether there were differences in the maximum strength between different groups of cardiovascular diseases.

\section{METHODS}

\section{Subjects involved}

Here are presented the patients recruited on the basis of the basic pathology: 45 patients (39 males and 6 females) had chronic heart failure (CHF) in clinical stability for at least 3 months, class NYHA II-III; 21 patients (16 males and 5 females) had peripheral obliterative arteriopathy with claudication (POAC, stage lla of Fontaine); 22 all male patients had undergone coronary angioplasty (coronary artery disease - CAD); 6 patients (4 males and 2 females) had undergone orthotopic cardiac transplant (HT) for at least 6 months.

Maximum strength estimate of the five muscles tested was significantly lower in patients diagnosed with heart disease compared to the control group. When patients were subdivided according to the type of disease, a clear trend among groups was displayed with maximum strength in lower limbs being higher in controls, followed by the CAD group, then CHF group, the HT group, and POAC group. In the upper limbs CAD was followed by POAC, while the order of the other groups remained unchanged.

\section{Strength evaluation}

The maximum strength of the quadriceps and the brachial biceps muscles was assessed by means of submaximal tests. The tests were deemed appropriate when, for a given load, the subject was able to carry out 10 or fewer repetitions of the movement before fatigue. Once the load and the number of repetitions valid for the test had been established, the following indirect formula was used to calculate the value of 1 repetition maximum (1 RM): Predicted 1 RM = Weight Lifted/1.0278-.0278X (where X is the number of reps performed) 17.

Therefore, predicted $1 \mathrm{RM}$ refers to the maximum weight estimate a person can lift only once in a comple te range of motion ${ }^{17}$. Maximum strength of each muscle was obtained through the normalization of $1 \mathrm{RM}(\mathrm{kg})$ by body weight $(\mathrm{kg})$ to avoid the influence of other variables such as muscle mass ${ }^{9}$. Average strength of the muscles of both right and left limbs was considered. During testing, the patient's electrocardiogram was constantly monitored telemetrically.

Strength testing, in which each exercise involves a contraction phase and a relaxation phase of 2 seconds, comprised. 
Before the measurement began, the subjects were instructed to warm up for about 10 min (including 5 min of cycling and 5 min of mobility and free movements of the arms and legs). After warming up, the subjects were familiarized with the device by performing 8-10 repetitions at the lowest load, then the load was gradually increased until reaching the optimal load. All tests were performed by the same two technicians. Only moderate standardized verbal encouragement was given to all participants during the test.

\section{Statistical Analysis}

All data were processed using the SPSS 18.0 program. Age and anthropometric characteristics are expressed as mean value \pm standard deviation. Comparisons between groups were analysed by unpaired $t$ test (2-sided) or Analysis of variance (one-way ANOVA) for comparisons with $>2$ subgroups. Bonferroni posthoc multiple comparisons were performed when appropriate. The alpha-error probability was set at $p<.05$ (2sided). When examining the difference between two conditions, effect size was calculated using Cohen's $d$. When variables were more than two, effect size was calculated using eta squared $\left(\square^{2}\right)$.

\section{RESULTS}

Group comparisons between patients overall and controls are shown in Figure 1 [ $\pm 95 \%$ confidence interval]. Maximum strength of quadriceps muscles was significantly lower in patients $(M=1.76 ; S D=.59)$ compared to the control group $(M=2.46 ; S D=.62)$ with a difference of $31 \%(p=.0001 ; d=1.15)$. Maximum strength of brachial biceps muscle was significantly lower in patients $(M=.19 ; S D=.03)$ compared to the control group (M=.13; $\mathrm{SD}=.03)$ with a difference of $32 \%(p<.0001 ; d=2.00)$.

One-way ANOVA showed between-group differences in maximum strength of both quadriceps $\left(F_{1,169}=14.37\right.$, $p=.0001)$ and brachial biceps $\left(F_{1,169}=27.21, p=.0001\right)$ muscles while there were no significant differences in maximum strength for the other muscles.

When patients were subdivided according to the type of disease, although strength differences were not always significant, a clear trend among groups was displayed with maximum strength being higher in controls, followed by the POAC group, then the CAD group, the CHF group, and the HT group $[ \pm 95 \%$ confidence interval]. The group of patients diagnosed with diabetes did not differ from other patients in maximum strength of both quadriceps $(p=.06)$ and brachial biceps $(p=.06)$ muscles respectively.

\section{DISCUSSION}

Cardiovascular rehabilitation is a well-established means of improving the functional capacity, physiological outcomes, quality of life and psychological well-being in patients with cardiovascular disease ${ }^{18-20}$. Resistance training is now recommended as a component of cardiac rehabilitation by the major guidelines ${ }^{1,2,19}$. As it happen in aerobic training, for a correct strength training prescription, it is necessary to be aware of the baseline status of the patients in order to develop a training program that effectively stresses peripheral muscles without creating cardiovascular overload. To our knowledge, no previous studies compared the baseline strength status in different types of chronic heart disease. Therefore, the purpose of the present study was to estimate maximum dynamic strength of the two primary antigravity muscles of upper and lower limbs in three categories of patients with chronic heart disease: POAC, CAD, CHF, and HT.

Unlike most of the studies reported in the literature, which have utilized isokinetic testing, our study evaluated patients by means of a different technique. We decided to evaluate dynamic maximum strength estimating 1 RM (using free weights and a machine) rather than assessing isokinetic force, work, and power or isometric 
force ${ }^{1}$. Our decision was dictated by the need to utilize a test that would be both simple and reliable, and which would require inexpensive equipment that enabled us to identify the training work-load and to formulate strength training prescriptions to be implemented not only in hospital but also in local gymnasiums ${ }^{16}$.
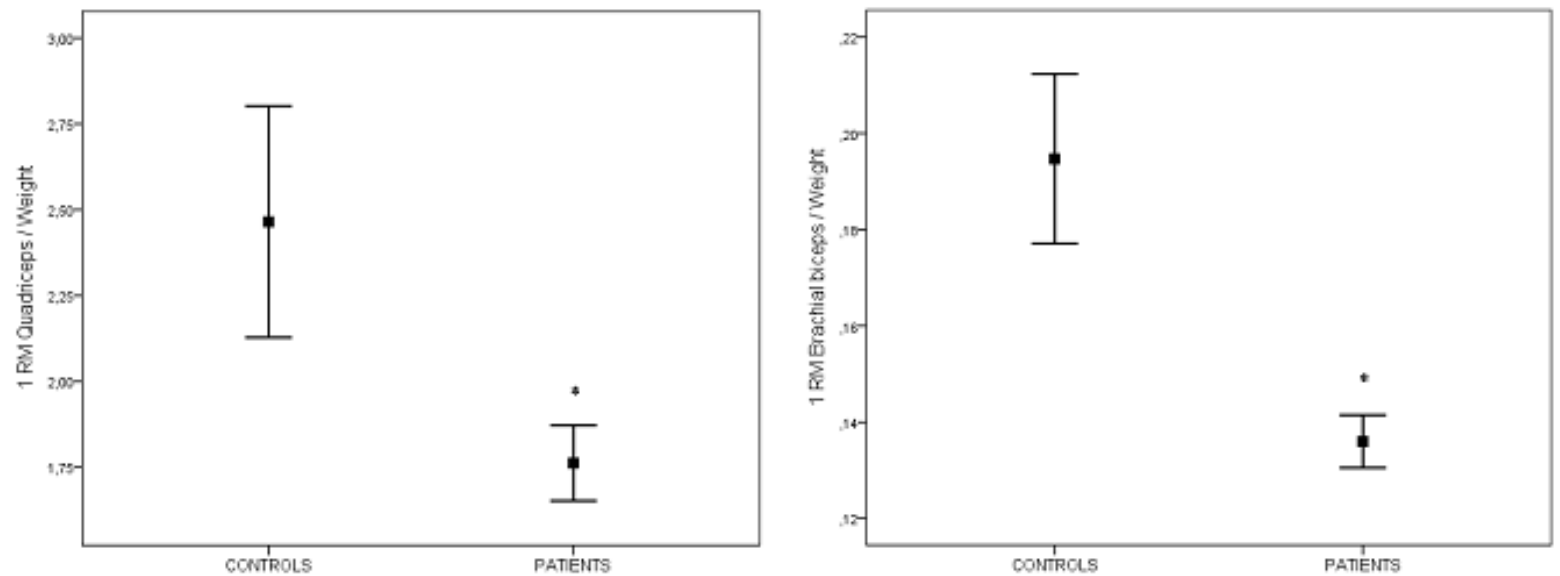

Note. ${ }^{*} p<.001$

Figure 1. Maximum strength estimate of the patients enrolled compared with a control group ( $\pm 95 \%$ confidence interval: mean \pm 2 standard error of mean)

Strength assessment revealed that the maximum strength of the heart disease patients was $28-32 \%$ less than that of a control group of age-matched healthy sedentary subjects (see Figure 1). This should come as no surprise since patients with chronic heart disease often experience impairment, functional limitation and disability due to deteriorating health. Since our patients expressed a great variability in type of disease, disease severity, and in the concurrence of other chronic conditions we decided to estimate maximum strength according to the type of heart disease.

When the patients were subdivided according to the disease, it clearly emerged that the strongest patients with regard to both the muscle groups were those in the POAC group, followed by CAD group, the CHF group, and then the HT group. This is the logical consequence of the history of the disease. Indeed, patients who undergo angioplasty often come in for the procedure without having ever suffered from any symptoms that might prompt them to limit their physical effort, or else with symptoms of recent onset. Moreover, hospitalizations are usually very short. At any rate, although CAD group was found to be the strongest group in patient sample, maximum strength of the lower limbs was significantly lower (19\%) than that of the control group. This finding seems to confirm the data of previous studies on strength in patients diagnosed with coronary disease: Ghroubi reported a 25\% strength deficit in the lower limbs on isokinetic testing ${ }^{21}$ and Gayda a diminished resistance to isometric effort22. The small discrepancy between the studies may be accounted for by the differences in strength testing technique as well as the control group: while we enrolled age matched healthy sedentary subjects with no previous muscle strength training experience, the above mentioned studies compared the patients to a group of physically active age matched controls.

The natural history of patients diagnosed with $\mathrm{CHF}$ is different: repeated hospitalizations together with the pivotal symptoms of heart failure, asthenia and effort dyspnea, prompt patients to limit themselves with regard not only to strenuous effort but also to moderate activity, even to the extent of impairing normal everyday actions in patients with longstanding disease. To this, we may add the effect of malnutrition, which 
complicates the clinical picture in patients who are in the most advanced functional class ${ }^{23}$. So, the fact that this group of patients reported a strength deficit of about $31 \%$ compared to the control group, is not surprising.

HT patients seem to be the weakest of all, even if data are not always significant owing to the small size of the sample and the variability in years of disease prior to the transplant. Nevertheless, HT is often an effective treatment option for patients with end-stage CHF. Most patients who undergo transplantation spend long periods in bed before the operation. Muscular weakness and fatigue are the primary limiting symptoms in the day to day activities of many of these patients. Moreover, the immunosuppressive and cortisone therapy required after transplantation weakens the muscles further. Back in the 1993, Braith et al. ${ }^{24}$ estimated that the quadriceps muscle strength of patients with $\mathrm{HT}$ is $60-70 \%$ of that in age-matched controls. Our study seems to consolidate this data but with a lower estimate of the deficit in HT recipients (52\%).

Summarizing, the present study showed that chronic cardiovascular patients are characterized by a muscular impairment that parallels the history of the disease: baseline strength status decreases with the increase of the disease severity.

To our knowledge, no previous studies measured maximum strength of small muscle groups in patients with chronic heart disease. The novelty of this study was not only to estimate the maximum strength of the quadriceps but also that of the brachial biceps in three categories of patients with chronic heart disease (CAD, $\mathrm{CHF}$, and $\mathrm{HT}$ ), which showed a similar trend of quadriceps muscle.

\section{IMPLICATIONS}

Resistance training is not only safe and practicable ${ }^{25}$ but it also plays a crucial role in cardiovascular rehabilitation setting. It has a lot of benefits such as enhancing muscular strength, functional capacity, independence, quality of life and reducing disability ${ }^{17}$. This study shows that patients with chronic heart disease have a strength impairment which parallels the history of disease. In our opinion this peripheral deconditioning requires a different approach in the rehabilitation setting. Different types of heart disease show a different trend of strength: it is therefore necessary to evaluate the strength baseline status to be able to train strength, identifying the most appropriate work-load. A strength training with lower loads for a more prolonged period of time seems advisable in the local gymnasium setting ${ }^{16}$. This lower intensity phase should yield an initial aerobic and strength reconditioning which is recommended before switching to higher intensity training 26 .

\section{LIMITATIONS}

This study presents other two limitations: a lack of data on body composition, and specifically on lean body mass; muscle biopsy was not performed to report on muscle physiology.

\section{CONCLUSIONS}

The maximum strength of both quadriceps and the brachial biceps muscles is significantly lower in patients diagnosed with chronic heart disease than in healthy control subjects. Moreover, it seems that chronic cardiovascular patients are characterized by a muscular impairment that parallels the history of the disease. This information should be kept in mind when planning a rehabilitation program. 


\section{CONTRIBUTION OF EACH AUTHOR}

STEFANO SCARPA, PH.D is the first author of the research. He is the guide, the supervisor of the project and the scientific coordinator of the research. He has developed, in particular, those parts of the research: data analyses and statistics, results, discussion, conclusions. He reviewed the final version of the article.

ALESSANDRA NART, PH.D is the second author of the research. He is the creator of the project. From a practical point of view he collected all data. He contributed to developed, in particular, those parts of the research: results and discussion.

\section{REFERENCES}

1. American College of Sports Medicine. ACSM's Guidelines for Exercise Testing and prescription. 7th ed. Philadelphia, Pa: Lippincott Williams and Wilkins, 2006.

2. American Association of Cardiovascular and Pulmonary Rehabilitation. Guidelines for Cardiac Rehabilitation and Secondary Prevention Programs. 4th ed. Champaign, III: Human Kinetics, 2004.

3. Ades PA, Savage PD, Brawner CA et al. Aerobic capacity in patients entering cardiac rehabilitation. Circulation 2006, 113:2706-2712. https://doi.org/10.1161/CIRCULATIONAHA.105.606624

4. Okada K, Naito AT, Higo T, et al. Wnt/B-Catenin Signaling Contributes to Skeletal Myopathy in Heart Failure via Direct Interaction With Forkhead Box O. Circ Heart Fail 2015; 8:799-808. https://doi.org/10.1161/CIRCHEARTFAILURE.114.001958

5. Drexler H. Peripheral circulatory adaptations to pump failure of the heart. Br Heart J 1994; 72:S22-27. https://doi.org/10.1136/hrt.72.2 Suppl.S22

6. Greising SM, Gransee HM, Mantilla CB, Sieck GC. Systems biology of skeletal muscle: fiber type as an organizing principle. Wiley Interdiscip Rev Syst Biol Med 2012; 4:457-473. https://doi.org/10.1002/wsbm.1184

7. Sullivan MJ, Green HJ, Cobb FR. Skeletal muscle biochemistry and histology in ambulatory patients with long-term heart failure. Circulation 1990; 81:518-527. https://doi.org/10.1161/01.CIR.81.2.518

8. Rantanen T. Muscle strength, disability and mortality. Scand J Med Sci Sports 2003;13:3-8. https://doi.org/10.1034/j.1600-0838.2003.00298.x

9. Hulsmann $M$, Quittan $M$, Berger $R$ et al. Muscle strength as a predictor of long-term survival in severe congestive heart failure. Eur $J$ Heart Fail 2004; 6:101-107. https://doi.org/10.1016/i.ejheart.2003.07.008

10. Izawa KP, Watanabe $S$, Osada $N$ et al. Handgrip strength as a predictor of prognosis in Japanese patients with congestive heart failure. Eur J Cardiovasc Prev Rehabil 2009; 16:21-27. https://doi.org/10.1097/HJR.0b013e32831269a3

11. Purser JL, Kuchibhatla MN, Fillenbaum GG, et al. Identifying frailty in hospitalized older adults with significant coronary artery disease. J Am Geriatr Soc 2006; 54:1674-1681. https://doi.org/10.1111/j.1532-5415.2006.00914.x

12. Ruiz JR, Sui $X$, Lobelo $F$ et al. Association between muscular strength and mortality in men: prospective cohort study. BMJ 2008; 337:92-95. https://doi.org/10.1136/bmi.a439

13. Metter EJ, Talbot LA, Schrager M, Conwit RA. Arm-cranking muscle power and arm isometric muscle strength are independent predictors of all-cause mortality in men. J Appl Physiol 2004; 96:814-821. https://doi.org/10.1152/japplphysiol.00370.2003 
14. Oliver D, Pflugfelder PW, McCartney N, et al. Acute cardiovascular responses to leg-press resistance exercise in heart transplant recipients. Int $J$ Cardiol 2001;81:61-74. https://doi.org/10.1016/S0167-5273(01)00529-0

15. World Health Organization. Global Recommendations on Physical Activity for Health. Switzerland: WHO Library Cataloguing-in-Publication Data, 2010.

16. Sarto P, Merlo L, Astolfo P, Sarto M, Bedin L, Noventa D for the Long Term Therapeutic Exercise Training (LoTTET) group. Comprehensive therapeutic program for cardiovascular patients: Role of a sports medicine unit in collaboration with local gymnasiums. J Cardiovasc Med 2009; 10:2733. https://doi.org/10.2459/JCM.0b013e32830eb715

17. Brzyski, M. Strength testing: Predicting a one-rep max from a reps-to-fatigue. J Phys Ed Rec Dance 1993; 64:88-90. https://doi.org/10.1080/07303084.1993.10606684

18. Izawa K, Hirano Y, Yamada S, Oka K, Omiya K, lijima S. Improvement in physiological outcomes and health-related quality of life following cardiac rehabilitation in patients with acute myocardial infarction. Circulation 2004; 68:315-320. https://doi.org/10.1253/circi.68.315

19. McKelvie RS, Teo KK, Roberts R, et al. Effects of exercise training in patients with heart failure: the Exercise Rehabilitation Trial (EXERT). Am Heart J 2002; 144:23-30. https://doi.org/10.1067/mhj.2002.123310

20. Williams $M$, Haskell W, Ades $P$ et al. Resistance exercise in individuals with and without cardiovascular disease: 2007 update. Circulation 2007; 116:572-584. https://doi.org/10.1161/CIRCULATIONAHA.107.185214

21. Ghroubi S, Chaari M, Elleuch $\mathrm{H}$ et al. The isokinetic assessment of peripheral muscle function in patients with coronary artery disease: Correlations with cardiorespiratory capacity. Ann Readapt Med Phys 2007; 50:295-301. https://doi.org/10.1016/j.annrmp.2007.03.012

22. Gayda M, Merzouk A, Choquet D, Doutrellot PL, Ahmaidi S. Aerobic capacity and peripheral skeletal muscle function in coronary artery disease male patients. Int J Sports Med 2003; 24:258263. https://doi.org/10.1055/s-2003-39507

23. Gualco A., Opasich C, Brazzo S et al. Metabolic frailty in malnourished heart failure patients. Monaldi Arch Chest Dis 2007; 68:115-120.

24. Braith RW, Limacher MC, Leggett SH, Pollock ML. Skeletal muscle strength in heart transplant recipients. J Heart Lung Transplant 1993;12:1018-1023.

25. Schmid J, Anderegg M, Romanens M et al. Combined endurance/resistance training early on, after a first myocardial infarction, does not induce negative left ventricular remodelling. Eur $\mathrm{J}$ Cardiovasc Prev Rehabil 2008; 15:341-346. https://doi.org/10.1097/HJR.0b013e3282f5dbf5

26. Volaklis KA, Tokmakidis, SP. Resistance exercise training in patients with heart failure. Sports Med 2005; 35:1085-1103. https://doi.org/10.2165/00007256-200535120-00006

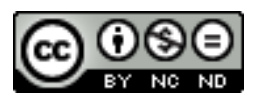

This work is licensed under a Attribution-NonCommercial-NoDerivatives 4.0 International (CC BY-NC-ND 4.0). 